\title{
Commentary
}

\section{Labor Inspection in a Privatized Health and Safety System}

\author{
By Frans Pennings, Professor of Labor Law and Social Security Law, Utrecht \\ University, the Netherlands / University of Gothenburg, Sweden
}

A defining characteristic of the Dutch Health and Safety Act is the choice of self-regulation by those bodies most able to ensure health and safety at the enterprise level. This legislation is characterized by provisions -referred to as goal provisions- that include objectives related to preventing or reducing risks to the health and safety of the workers. The provisions do not mention precisely how these goals are to be reached, as the choice for these methods is left to the social partners. Consequently, the employer or employers and the representative bodies of the workers, trade unions, or works councils need to establish healthy and safety policy, regulations, and any necessary measures. These are laid down in so-called ARBO (Occupational Health and Safety) catalogues, which are the result of negotiations of both sides of industry. At the end of the day, however, it is the employer that is obliged to take the concrete measures to implement the relevant regulations, in particular, the Occupational Health and Safety catalogue. These regulations, which private actors rather than the government adopt, intend to stimulate private parties to fulfill their responsibility and develop standards calibrated to the enterprise that also elaborate the standards laid down in the Act.

Restricted public interference is evident not only in this approach to law making, but also in the number of labor inspectors and their ways of supervising. Leaving room for private actors to decide for themselves and for parallel reductions in government expenditures on labor inspection have led to decreases capacity, which in turn has instigated trade union to complain about the limited capacity and functioning of labor inspectors. In 2014, complaints were received by the ILO Committee on the Application of Standards and 
Recommendations, which led to recommendations by the Committee to the Dutch government. Dutch trade unions now have made critical observations to how the Dutch government reacted to the recommendation, in particular that the workload and inspection methods are not consistent with the following ILO Conventions: Labour Inspection in Industry and Commerce (No. 81); Labour Inspection in Agriculture (No. 129); Occupational Safety and Health Convention and the Working Environment of (No. 155).

In their follow-up complaint to the Committee, the Dutch trade unions argued, inter alia, that the reduced role of government in inspections had led to reduced protection of employees. Employers invest less in safety and health and do not comply with basic prevention rules, such as making risk assessment plans. Fewer and fewer enterprises were visited outside the high-risk sectors and fewer and fewer unannounced visits took place.

\section{Analysis}

A number of issues were raised. The most important ones follow.

\section{Time Available to Fulfill Core Inspectorate Duties}

Article 10 of Convention 81 reads that the number of labor inspectors shall be enough to secure the effective discharge of the duties of the inspectorate. This provision, and Article 3, also lists the critical duties to be fulfilled for which a specified number of inspectors is required. The functions are to secure enforcement of the legal provisions relating to conditions of work and the protection of workers while engaged in their work, to supply technical information and advice to employers and workers concerning the most effective ways of complying with the legal provisions, and to bring to the notice of the competent authority defects or abuses not specifically covered by existing legal provisions.

The trade unions complained that the labor inspectors spent a large part of their time on administrative tasks rather than on these enforcement duties. Some discussion on how much time is exactly spent on these tasks aside; the issue shows a tension between the requirements of the Convention on actual enforcement and the way the Dutch system leaves the initiative to elaborate health and safety private parties. The Committee of Experts asks the government to respond to the criticism of the trade unions and to provide more information on the time spent on administrative tasks and to ensure an adequate number of inspectors. 


\section{Cooperation between Labor Inspections and Other Institutions}

The trade unions also raised the issue, covered in Article 5a, that enforcement is lacking, and that health and safety supervision is left to private services. These measures, according to the unions, do not adequately address risk prevention, instead focusing on reducing absence from work. The Committee invites the government to discuss with the social partners how to improve cooperation between the various services and how to provide effective detailed information on such cooperation.

\section{Number and Frequency of Labor Inspections}

The unions also observed that the number of inspectors was decreasing (from thirty-nine thousand to twenty-three thousand between 2005 and 2013), and that inspections focused on high-risk companies, leaving other companies underinspected. Small enterprises (with fewer than twenty employees) were not inspected at all. The Dutch government argued that, given the particularities of the Dutch system, fewer inspections do not mean a drop in the quality of enforcement or in compliance with laws and regulations. Fewer inspections are rather a consequence of the efficient deployment of inspection capacity and the active involvement of companies and social partners to tackle occupational health and safety issues.

The Committee replied to this argument that the involvement of the social partners and enterprises in compliance monitoring and assessment cannot replace the compliance and enforcement functions of the labor inspectorate. The unions argued that a significant number of employers do not comply with their obligations under health and safety and working time law. The Committee asked the government to respond to this claim. The Committee requested the government to continue to provide statistics on the activities of the labor inspection services. These statistics were to include the number of workplaces that meet the criteria for inspection and the workers employed there, the number of labor inspections, the number of violations detected and the penalties imposed, as well as the number of industrial accidents and cases of occupational diseases. The Committee further requested the government to aggregate the number of inspections by indicating the number in high-risk sectors and in small and medium-sized enterprises and to provide information on the number of those carried out following complaints by workers in small enterprises, and the number concerning the compliance of employers with regard to risk assessments and their obligations under the Working Conditions Act to seek expert OSH assistance. 


\section{Relevance of Report and Conclusions}

A report of the Committee of Experts is, of course, not a judgment in the sense of a decision of a court or tribunal. It in fact requires governments to remain in discussion with the ILO office and, in this case, also with national social partners and to provide the required information. Providing this information is especially critical in a privatized system, where it is often difficult to obtain.

At the background of the discussion is the larger room for private actors in the area of health and safety, the reduced role of the government, the policy of reticence in interfering in private issues, and the involvement of commercial services that undertake health and safety issues in enterprises. These private elements are allowed under the ILO conventions, but the state remains responsible for actual supervision of the obligations following from the Treaty. The precise wording of the duties of the labor inspection is therefore highly relevant. Because the Dutch government needs to find a solution for the gaps in the current system, which will entail appointing more inspectors and having them supervise the enterprises more closely, which by definition restricts the purview previously assigned to private actors. Indirectly, then, assigning greater responsibility to the government reinforces the approach found in the Committee of Experts reports: privatization is not forbidden but the state is ultimately responsible. The conventions detail the related obligations, and thus clarify this general recommendation. 